\title{
LA TRINIDADAD MONOTEÍSTA: JUDAÍSMO, CRISTIANISMO E ISLAMISMO
}

\author{
Lic. D. ${ }^{a}{ }^{a}{ }^{a}$ del Aguila Boge Pineda \\ Asociación de Prensa Argentina
}

\section{EL JUDAÍSMO}

Proyectadas bajo las sombras alargadas de las pirámides faraónicas de Atón, las tres religiones monoteístas mayoritarias, judaísmo cristianismo e islamismo, nacen a tiro de piedra unas de otras como espejismos de las arenas desérticas de la península arábiga.

Semitas bíblicos hijos de Sem hijo de Aram, escribieron en arameo, lengua imperial que abarcaba el siríaco caldeo asirio hebreo y árabe, la saga de su etnia. Una accidentada historia de cautiverios y repatriaciones, su particular interpretación de la creación del mundo, la confesión introspectiva y contrita de sus pecados errores y desviaciones en el trato directo con su Dios, los terribles anatemas de sus profetas. Conmovedora historia humana, si prescindimos de las exégesis posteriores, que le restan grandiosidad.

Ingente obra literaria, el Antiguo Testamento cuenta con el mayor número de traducciones y reediciones. Su denso lenguaje poético, tanto sacro como profano, ha influído en las Letras de todos los pueblos de occidente, de lo que tal vez la lengua española sea el exponente más ajustado; así como Homero sigue influyendo en la épica universal.

E1 elitismo endogámico del llamado a sí mismo Pueblo elegido de Dios, se circunscribía al reino de Israel. De unidad y unicidad étnica y religiosa, el judaismo apenas va a extenderse más allá de su propia raza y territorialidad. El sincronismo aperturista de Salomón, que pudo haber conseguido un imperio, fue anatematizado por los profetas.

Cultura tan patriarcal como matriarcal, da una gran preeminencia a la mujer: Sara, esposa de Abraham, madre de Isaac, salvado del sacrificio por orden de Dios; Agar, la concubina egipcia madre del primogénito Ismael, ambos arrojados del seno familiar. Rebeca, mujer del amnistiado Isaac. Raquel, mujer de Jacob, padre de las doce tribus de Israel. Rut la moabita, abuela del rey David. Betsabé, la adúltera y luego reina, madre de Salomón. La joven viuda Judit, que seduce a Holefernes para decapitarlo. Esther, la cautiva que llega a desposarse con el gran rey Asuero, que tras su conquista de Babilonia repatría al pueblo Judio y permite reconstruir el templo de Salomón, destruído por Nabucodonosor. 
A pesar de ciertas afinidades teosóficas del pensamiento Judío con el de Platón y Aristóteles, muy otro curso hubiera seguido la Historia si Antíoco IV al erigir en el Templo al Zeus Olimpico, hubiera conseguido helenizar a Israel. Las Escrituras traducidas, y los Evangelios ya en tiempos cristianos, se van a divulgar en griego.

Bajo la dominación romana, el emperador Tito destruye definitivamente el templo y la ciudad santa de Jerusalén en el año setenta de la Era Cristiana, causando la diáspora más larga de todos los tiempos, hasta nuestros días. Muchos judíos son deportados a Hispania, que ellos, con sonoridad de vocablo del Cantar de los cantares, llaman Sefarad, que va a ser su patria durante más tiempo que el que transcurre entre el asentamiento de Abraham, el emigrante más afortunado de la historia, en las tierras de Canaán, donadas por Dios, y la esclavitud en Egipto; o de la monarquía hasta la Diáspora.

Del Templo, tantas veces saqueado o destruído, sólo les quedaría una pared en la que lamentarse durante veinte siglos. Sin embargo, en este fenómeno único de incoluminidad e indisolubilidad tanto en tiempo como en espacio, el pueblo judio continúa cohesionado por sus propias leyes ancestrales: la Torah y el Talmud. Es la religión Padre.

\section{EL CRISTIANISMO}

El último profeta del Antiguo Testamento, Jesús de Nazaret, se proclama el Mesías esperado de Israel, Hijo de Dios y Salvador de los hombres. A pesar de su inapelable defensa de que su reino no es de este mundo, el procurador romano le condena a crucifixión por Rex judeorum, junto con su propio pueblo por impostor. Pero es precisamente la doctrina del manso nazareno la que va a socavar los cimientos del imperio más grande del mundo de sus tiempos. La fecha de nacimiento del Mesías no aceptado por los suyos, marcará una nueva Era para todo el Occidente. Es la religión Hijo.

Pablo de Tarso, judío y ciudadano romano, exime a los gentiles del estigma de la circuncisión y abre las puertas de la nueva iglesia universal, de la que Roma va a ser su capital. Los apóstoles cristianizan toda el Asia Menor hasta Armenia. Llegan a Etiopía Atenas y Alejandría y desde Roma el cristianismo se extiende hasta los más remotos confines del imperio: Hispania, las Galias, Bretaña, llenando sus tierras de mártires, santos y anacoretas. Ya cristianizado el imperio, Cosntantino el Grande, en el año 313 promulga la tolerancia con el Edicto de Milán, y asienta su corte en la Bizancio griega, ahora Constantinopla.

El emperador Teodosio, "que viene de España, país que se caracteriza por su incultura", escribe Libanio a Prisco, ambos eminentes helenistas, con el Edicto de Tesalónica en el 380 , decreta el cristianismo religión del Imperio y lo divide en oriental y occidental. Una extensa geografia en la que Papas y Patriarcas, prelados y abades, templos basilicas monasterios y sedes episcopales rivalizan con el trono en riqueza y poder: Eusebio y Basilio, Atanasio y Arrio, que niega la divinidad de Cristo. Estas divisiones politicas y religiosas llevan al Imperio al borde de sí mismo. Se produce el Cisma de Occidente. Y es entonces cuando la Iglesia, como poder temporal, sirve de cohesión para prolongarlo más allá de su propia agonía. Surgen padres de la Iglesia como San Agustín de Hipona en África y San Ambrosio en Milán. 
Bárbaros godos, vándalos germanos escitas y eslavos, han adoptado el arrianismo, traido a España desde las Galias por los visigodos. Cristianos norteafricanos establecen en la península la iglesia latina, que cuenta con la primera sede episcopal en Guadix. Finalmente, el rey visigodo arriano, Recaredo, decreta el cristianismo romano religión oficial de España. A esto ha contribuido, si creemos en el potencial metafisico del martirio, la muerte de su hermano San Hermenegildo.

En el siglo IX de la Era Cristiana, Carlomagno es coronado emperador del Sacro Imperio Romano Germánico, que reúne a príncipes, condes y señores feudales de toda Europa. Los Cruzados ponen sus metas en el Oriente Medio para reconquistar los Santos Lugares, en poder del islam. Pronto atacan al rico y culto hermano Imperio Bizantino, ya desgajado por la Iglesia Ortodoxa y lenguas escritas con caracteres ciŕlicos griegos.

El Imperio Bizantino, debilitado por las continuas guerras contra escitas y eslavos por el norte y cristianos y latinos por el oeste, sucumbe finalmente con la toma de Constantinopla en 1453 por los turcos islamizados, que heredan lo que había sido el imperio romano oriental: Bulgaria, Rumanía, Hungría, y los que constituyen los paises Balcánicos.

A principios de la Edad Moderna, el cristianismo sufre otra tremenda y transcendental escisión, que Carlos $\mathrm{V}$ no consigue atajar. Un religioso alemán, Martín Lutero, propone la reforma de la iglesia vaticana. El Protestantismo es aceptado mayoritariamente por los pueblos europeos no latinos. Los anglosajones transplatan su cristianismo reformado a la mitad norte del recién descubierto continente; los españoles evangelizan el catolicismo en el centro $y$ en el sur.

\section{EL ISLAM}

En el siglo VII de la Era Cristiana, un hijo del desierto, descendiente del primogénito de Abraham, Ismael, y de la egipcia Agar, por lo que sus adeptos se llamarán ismaelitas o agarenos; o quizás descendiente de Quetura, la concubina árabe de Abraham, madre de las tribus del norte, con la Hégira islámica funda la religión que bien podríamos llamar del Espiritu Santo.

Mahoma, incendiado por la llama divina, como las columnas de fuego que habían guiado por el desierto a las huestes de Israel, no osa proclamarse Mesias, ni Hijo de Dios, sino sólo su Profeta, y como Cristo, sube al cielo desde una colina de Jerusalén. Promueve y acaudilla la guerra santa y promete a los caídos en ella el Paraíso y las huries de Allah.

Autodidacta iluminado, escribe una nueva Torah que llama Corán, la obra sacra que cinco veces al día leen o recitan los cerca de cien millones de musulmanes de nuestros tiempos. Los sensuales y desenfadados cuentos de Las mil y una noches constituyen la saga profana de un inabarcable ámbito lingüístico. El español conserva un rico acervo léxico de él.

Ceñidos de alfanjes y cimitarras, tocados con. turbantes, montados en caballos árabes, sus ejércitos van engrosándose en una marcha fulminante al grito de Allah Akbar: Siria Persia India Indonesia, Turquía, Arabia Egipto Sudán, el Sáhara y el Magreb. Todo el continente negro, excepto algunos grupos de hechiceros animistas del Africa profunda. 
Por el estrecho de Gibraltar entran en la Península Ibérica, que recorren victoriosamente. Los cristianos quedan constreñidos en las estribaciones cantábricas. Cruzan los Pirineos hasta que Carlos Martel contiene su avance en Poitiers. Desde Covadonga D. Pelayo inicia una reconquista que se prolonga durante ocho siglos. Al-Andalus florece con suntuosos palacios, mezquitas y minaretes, desde donde el almuédano ensordece el Padrenuestro y el Credo. Córdoba, su capital, emula a Damasco, La Meca y Bagdad. El califa Al-Hakam II acumula la biblioteca más rica en ciencias y saberes del mundo conocido. Tanto judíos como cristianos se arabizan; El Cid y los reyes Alfonsos, el Sabio y D. Pedro el Cruel, con su alcázar mora en Sevilla. Es el suelo donde la religión trilliza se tolera a sí misma más o menos.

Mientras tanto el tártaro Tamerlán ha creado un gran imperio islamizado que los mongoles van a continuar: Afganistán, Irak Irán, la India, las grandes islas del océano Indico, se llenan de la admirable arquitectura de las mezquitas, en pugna con las catedrales góticas, que en España crea el peculiar estilo mudéjar. Sin embargo, el Egipto islamizado, conserva su arquitectura faraónica, sin huellas ya de su antigua religión.

La cristianisima Turquía hace ya tiempo que reza a Allah. Con la conquista de Constantinopla ahora Estanbul, el Imperio Otomano se apropia la Europa bizantina oriental, hasta las puertas de la también imperial Viena. El Papa Pio V convoca la Santa Liga, con España y Venecia. En el golfo de Lepanto en 1571 se entrecruzan a muerte más que nunca los estandartes de la Media Luna y la Cruz. La victoria cristiana les pone un freno. Pero el imperio Otomano sigue latente hasta finalizada la primera guerra mundial en los comienzos del siglo XX. Retrocede entonces hacia Asia Menor, y atomizado en emiratos sultanatos y pequeñas monarquias occidentalizadas, soportan un régimen cuyos protectorados no los van a llevar a la estabilidad.

Por todas partes por las que han pasado los consecutivos imperios árabes, han ido dejando huellas indelebles y latentes de su cultura, lengua y religión.

\section{PARALELISMOS}

En el siglo XIX, Francia Holanda Alemania Italia e Inglaterra, acaban de repartirse el continente africano, como anteriormente se habían repartido parte de Asia, Junto con España y Portugal. No exentos de una intención misionero-cultural, científico-tecnológica y capitalista-comercial. En los años sesenta del siglo XX, las Naciones Unidas, de las que ya forman parte muchos de esos pueblos, en los que artificialmente han sido fundidas etnias y tribus rivales, tras un periodo de autonomías consiguen su independencia.

Los invasores introducen el cristianismo, tanto católico como protestante, según el país colonizador, que junto con el Islam anterior continentalizado, conviven con el animismo original. Es dificil creer que en la India, con cuatrocientos millones de hinduistas, sólo existan tres millones de budistas, frente a sesenta millones de mahometanos. Tras su independencia de Inglaterra a mediados de siglo XX, Pakistán y Bangla Desh también se independizan como Estados islámicos. En la católica Filipinas de las crucifixiones en viernes santo, la isla de Mindanao ahora intenta conseguir su independencia esgrimiendo la misma razón. Alli el papa Pablo VI en 1970 sufrió un atentado del que resultó ileso. Poco después Juan Pablo II es herido gravemente por un turco musulmán en la Plaza de San Pedro. 
Frente a las dos religiones monoteístas imperiales, cristianismo e islamismo, el restringido judaismo tiene su mayor exponente en los Estados Unidos, a pesar de considerarse minoría. Cuando el rey D. Juan Carlos hizo la primera y transcendental apología de la expulsión de los judíos de España en la sinagoga sefardita de Westwood, California 1987, aparte de los periodistas de la comitiva real, aterrorizados por el terremoto que aquellla mañana nos despertó, yo fui la única española residente invitada por el rabino Dr. Ott.

La fundación del Estado de Israel en Palestina en 1948, alentado por un sionismo onírico coincidente con el horror del holocausto nazi, es el acto más inconsciente o solapado del antisemitismo histórico internacional. A principios de este III Milenio, que arrastra aún el fundamentalismo político-religioso entre las tres religiones entroncadas, todas las naciones concuerdan en que debe ser proclamado un Estado Palestino, tras haber permitido su dispersión.

El islamismo, más cercano racial y territorialmente al judaísmo que al cristianismo, aunque nacido en oriente religión occidental, tienen en común la circuncisión, adoptada por Abraham al volver de Egipto, donde se practicaba. Como diferencia, la ablación femenina es sólo practicada por los musulmanes, aún en nuestros días, adoptada, según parece, de los pueblos nilóticos y sudaneses conquistados por el Islam. Estas mujeres tienen que subrogar el goce de su libido para el Paraíso de Allah. Con ventaja, las cristianas pueden gozarlo sólo en el santo matrimonio.

Judaísmo y cristianismo tienen en común la monogamia, contra la poligamia mahometana. Mientras el Pueblo de Dios prefiere conservar su pureza racial y religiosa, el cristianismo tuvo misioneros, avanzadillas de imperios, y el Islam tiene conquistadores guerreros defensores de su Fe. judíos y mahometanos consideran al cerdo animal impuro. Pero, ¡oh, lo que los católicos españoles hacen de las patas del ibérico animal! El Corán prohibe el alcohol, los judíos lo consumen moderadamente, y los cristianos hacemos un uso báquico de él. Equitativamente nos repartimos el viernes sábado o domingo como fiestas de guardar.

E1 exacerbado antropomorfismo católico, sólo superado por hinduístas y budistas, es la antítesis de la iconoclastia de sus dos co-religiones hermanas y de su clonación protestante. Cuando los españoles llegan al Nuevo Continente se escandalizan de las representaciones zoomórficas de las religiones autóctonas, y los ídolos son destruídos como engendros del diablo.

A lo largo de los tiempos, las tres religiones han ido experimentando, como todo ente vivo, un inexorable proceso de división celular. Después de cuarenta siglos, los judíos siguen esperando a su Mesías. Y los drusos sufies, Mendigos del Amor, esperan al suyo, que será arrojado por el ano, y que salvará a la Humanidad.

\section{CONCLUSIÓN}

Entre las infinitas definiciones con las que los hombres conciben a Dios: el Oculto, de Atón, el Óptimo Bien o la Verdad Suprema, de Platón; el Dios esencia y no presencia, porque entre Dios y las criaturas no hay semejanzas posibles; la emanencia y permanencia del 
motor mecánico del universo; la eternidad del mundo de Aristóteles y Averroes, está el Dios metafisica e intelecto adquirido, que se identifica con el intelecto universal.

Según la cosmogonía hindú, la Creación durará dos mil ciento sesenta millones de años, y después de arrasado todo y de la destrucción total, Brahma despertará y creará de nuevo el universo con la sustancia primitiva. E1 héroe y dios Mitra mesopotámico, cuyos sacerdotes usaban tonsura, nace de un rayo un 25 de diciembre, observado por unos pastores, y es llamado al cielo tras una comida sacramental de palabras eucarísticas, profetiza que al final de los tiempos todos saldremos de las tumbas, que el mal será destruído y que el bien vivirá para siempre. El persa Zaratustra, con su doctrina de sabiduría y pureza y la dicotomía del bien y del mal, coincide en que con el tiempo del bien ocurrirá la reconstrucción del mundo, que durará eternamente.

Cinco siglos antes de Cristo, Buda había sido concebido en el costado de su madre, y nace por vía no natural. Un viejo sabio quiso ver al niño, y transportado por los aires sobre los Himalayas, llega hasta cerca del Nepal. Alli coge en sus brazos al bebé divino y llora, porque él no vivirá para conocer sus enseñanzas: La supresión de todo deseo hasta alcanzar el Vacio Brillante: la Iluminación

San Agustín concibe a Dios como la interioridad humana donde habita el Absoluto. Hegel, como lo totalmente espiritual en su desarrollo de ser y existir. E1 gran Maimónides, judío sefardita cordobés del siglo XII, huyendo de la persecución almohade no menos que de la intolerancia de los judios cabalistas de Barcelona y Provenza, se refugia en Fez, en el Magreb de donde precisamente proceden los almohades, lugar que siempre acogió a perseguidos y refugiados de las tres religiones hermanas. E1 sabio racionalista, llamado segundo Moisés, establece como figurado y alegórico el antropomorfismo de la Biblia. Y cree que el cristianismo y el mahometanismo son caminos para traer al verdadero rey Mesías. Concuerda con los anteriores y con el profeta Isaias, en que en esa época no habrá guerras, ni hambre, ni conflictos, y que las bendiciones serán abudantes.

Desde el insuperable Dios es Amor, antitético del Apocalipsis del mismo San Juan Evangelista, desembocamos en la dinámica sempiterna del Dios deseante y deseado de Juan Ramón Jiménez.

Contando con los dos mil ciento sesenta millones de años, que según los hinduistas durará la Creación, desgraciadamente no parece que esa época idilica por tantos profetizada, sea inminente en llegar, "en estos tiempos en que el hombre, cada vez más, va dejando de ser Dios para convertirse en neutrones". 